\title{
A new species of the genus Wendilgarda (Araneae: Theridiosomatidae) from Japan
}

\author{
Yuya Suzuki \\ Graduate School of Life and Environmental Sciences, University of Tsukuba, 1-1-1 Tennodai, \\ Tsukuba, Ibaraki 305-8572, Japan \\ Email: sasaganiya1206@gmail.com
}

\begin{abstract}
A new species of the genus Wendilgarda is described as Wendilgarda ruficeps sp. nov. from Japan. Both sexes of this species possess a bicolor body: prosoma reddish orange and opithosoma dark grey, which is useful for distinction from other congeners. The male palpal morphology of this species is similar to that of $W$. sinensis and $W$. muji, but can clearly be distinguished by the serrated edge on the posterior side of the median apophysis. The female epigyne of this species is similar to that of $W$. sinensis; however, it shows the smaller invagination on the posterior margin of the epigyne and the wider scape.
\end{abstract}

Key words - Ibaraki Prefecture, morphology, Okayama Prefecture, taxonomy, Tokyo, Wendilgarda ruficeps

\section{Introduction}

The genus Wendilgarda Keyserling 1886 (Araneae: Theridiosomatidae) consists of tiny spiders, which are known to construct webs with unique architecture on the water surface (Coddington 1986). Seven of the 13 known species of the genus have been recorded from East to Southeast Asia (World Spider Catalog 2019). To date, only one species of this genus, W. nipponica Shinkai 2009, has been recognized in the Japanese fauna (Shinkai 2009). This species is recorded from Honshu, Shikoku, and Tokara Islands (Shinkai 2009; Suguro 2014) and inhabits beside streams (Shinkai 2009).

Recently, I got some specimens of the Wendilgarda species that present characteristic bicolor body, from a pondside in Ibaraki Prefecture. After that, I had a chance to observe unidentified specimens from Okayama Prefecture collected by Mr. Kouichi Nojima in 1993, which are similar to my specimens in appearance. Morphological observation of the specimens from Ibaraki and Okayama Prefectures revealed that these specimens are conspecific with each other, and they belong to a species new to science; thus, it is described in this paper.

\section{Materials and Methods}

All specimens were preserved in $80 \%(\mathrm{v} / \mathrm{v})$ ethanol, their morphological features were observed under a stereoscopic microscope (Nikon AZ100M, Japan), and photographs were taken with microscope imaging software (Nikon NIS-Elements D 4.20.00 64-bit, Japan). Specimens of the type series designated in this paper and other specimens used for morphological measurements have been deposited in the collection of the National Museum of Nature and Science, Tsukuba.
Measurements are given in $\mathrm{mm}$. The value ranges of measurements are indicated in parentheses. Measurements of legs are given in the following format: [tarsus + metatarsus + tibia + patella + femur $=$ total]. The names of each part of the male palp and female epigyne are given according to Miller et al. (2009).

\section{Taxonomy}

Family Theridiosomatidae Simon 1881

[Japanese name: Karakara-gumo-ka] Genus Wendilgarda Keyserling 1886

[Japanese name: Naruko-gumo-zoku]

Wendilgarda ruficeps sp. nov.

[Japanese name: Muna-aka-naruko-gumo]

(Figs. 1-3)

Type series. Holotype: $\widehat{\jmath}$, Nakao, Okayama City, Okayama Pref., 9-VI-1993, K. Nojima leg. Paratypes: $2{ }^{\Uparrow} 1$ 우, same

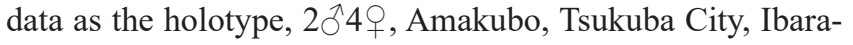
ki Pref., 15-V-2019, Y. Suzuki leg.

Other specimens examined. 1 , , Kishi, Musashimurayama City, Tokyo, 27-IV-2014, T. Ichikawa leg. 3 ${ }^{\lambda}$, Amakubo, Tsukuba City, Ibaraki Pref. 20-V-2016, Y. Suzuki leg. 1亏., Kaname, Tsukuba City, Ibaraki Pref., 3-VI-2017, Y. Suzuki leg. $50^{1} 9$ 우, Amakubo, Tsukuba City, Ibaraki Pref., 15V-2019, Y. Suzuki leg.

Specimens other than used for morphological measurements

20 17 17 , Amakubo, Tsukuba City, Ibaraki Pref., 15-V2019, Y. Suzuki leg. $1{ }^{\Uparrow} 1$ \% , Kamoike, Katano- machi, Kaga City, Ishikawa Pref., 24-VI-2019, Y. G. Baba leg. All of these specimens have been kept in the author's private collections. 


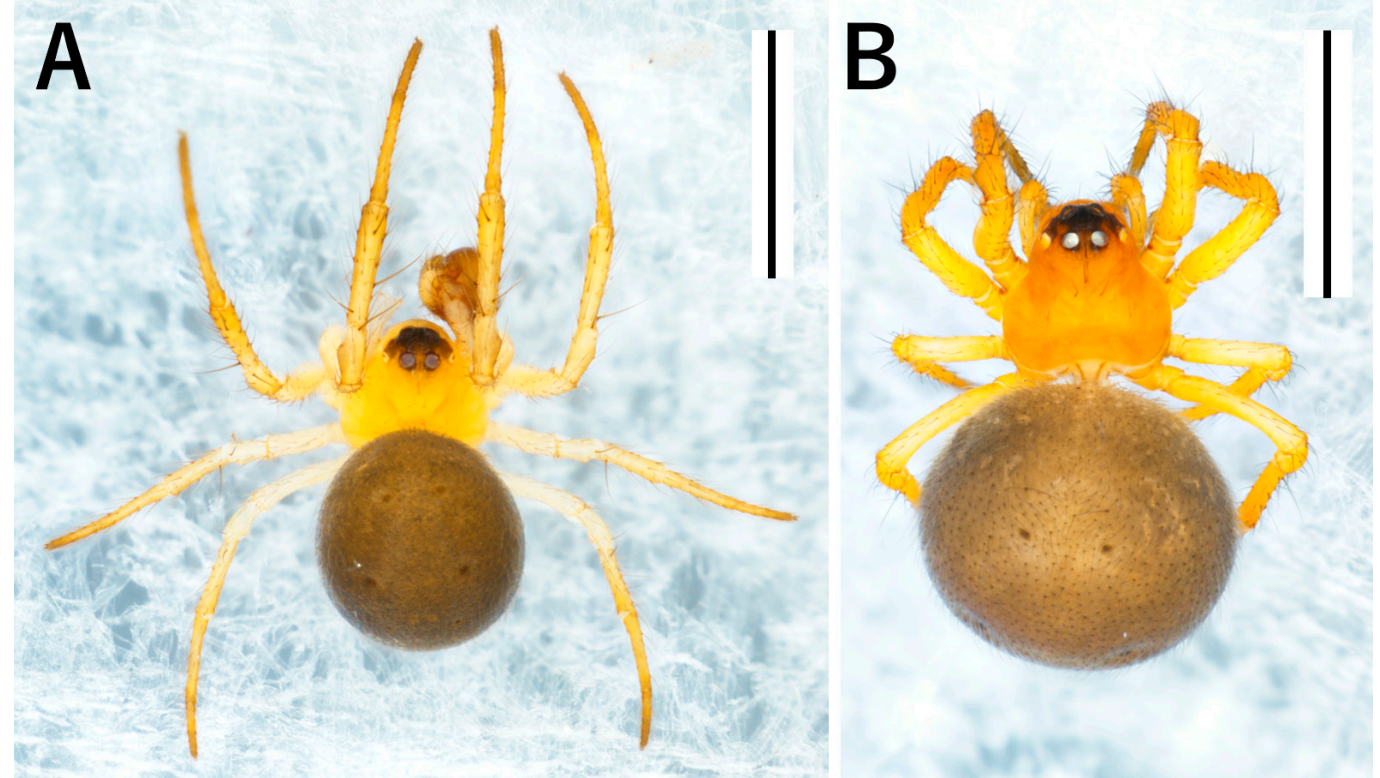

Fig. 1. Wendilgarda ruficeps sp. nov. A, habitus of male (holotype); B, habitus of female (one of paratypes from Ibaraki Pref.). Scale $=1.0 \mathrm{~mm}$.

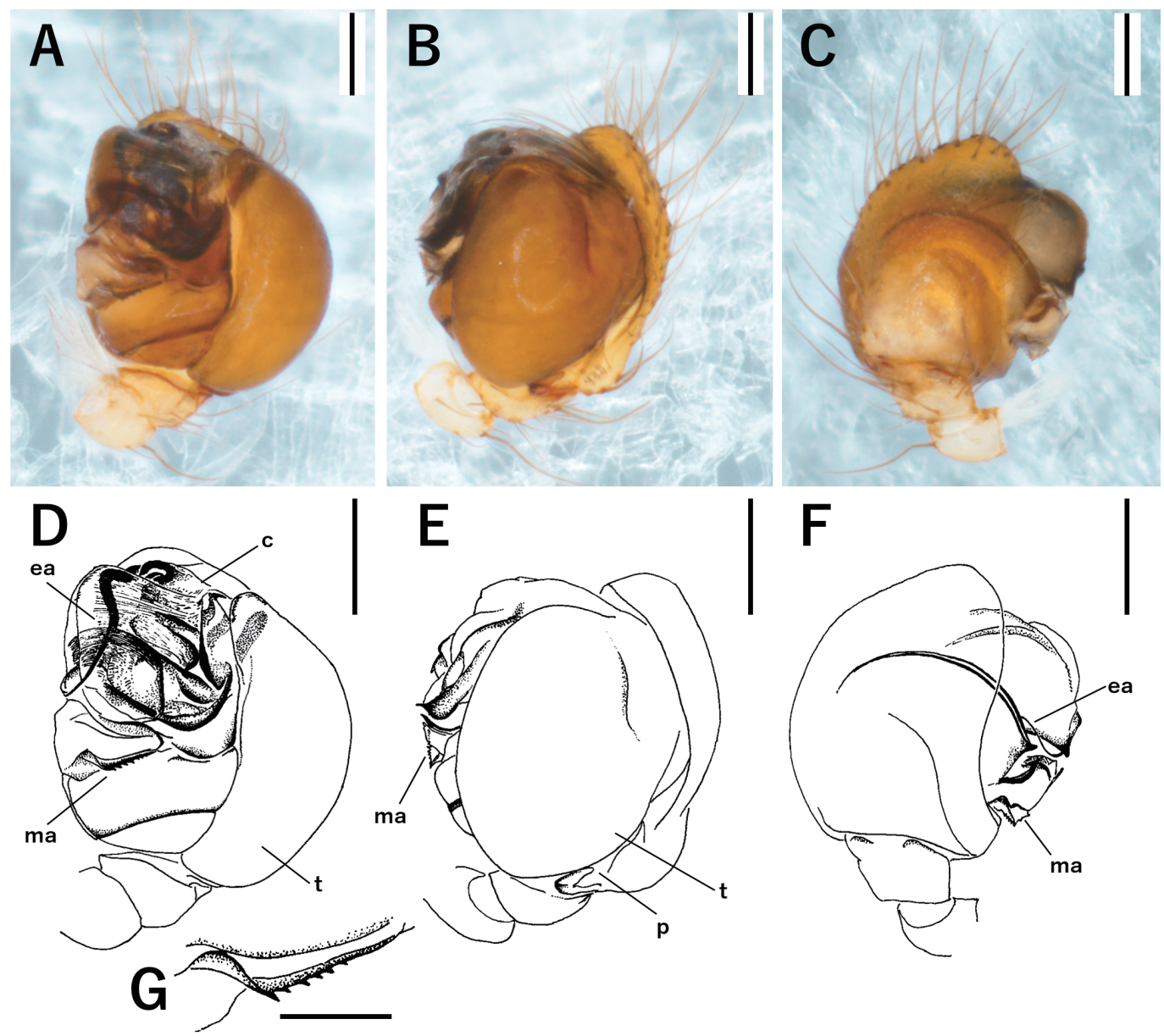

Fig. 2. Left male palp of Wendilgarda ruficeps sp. nov. (holotype) (A-F) and magnified view of median apophysis (G). A, D, G, ventral view; B, E, retrolateral view; C, F, prolateral view. Abbreviations: c, conductor; ea, embolic apophysis; ma, median apophysis; $p$, paracymbium; t, tegulum. Scale $=0.1 \mathrm{~mm}(\mathrm{~A}-\mathrm{F}), 0.05 \mathrm{~mm}(\mathrm{G})$. 

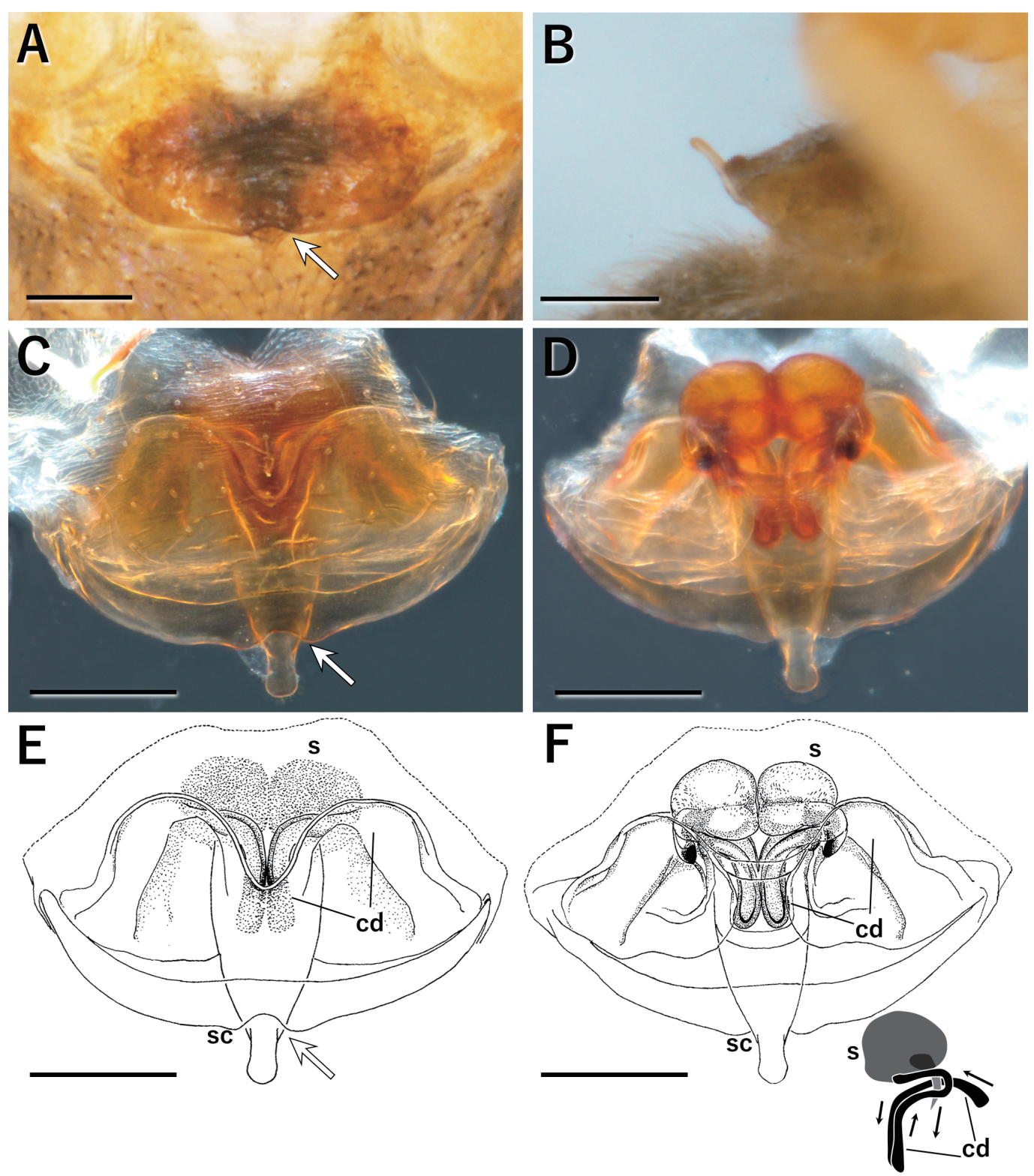

Fig. 3. Female genitalia of Wendilgarda ruficeps sp. nov. (A-B and C-F are of different specimens of paratypes: the former is from Ibaraki Pref., which is corresponds to Fig. 1B and the latter is from Okayama Pref.) A-B, epigyne; A, ventral view; B, lateral view; C-F, clarified epigyne: C, E, ventral view, D, F, dorsal view. Abbreviations: cd, copulatory duct; s, spermatheca; sc, scape. Scale $=0.1 \mathrm{~mm}$.

Diagnosis. In general appearance, the species can clearly be distinguished from other species of the genus by the bicolor body of fresh specimens: prosoma reddish orange and opisthosoma dark grey. Although old specimens (collected 26 years ago) were decolorized compared to fresh specimens, the bicolor pattern is retained (Fig. 1). Male palpal morphology of this species resembles that of $W$. sinensis Zhu \& Wang 1992 and W. muji Miller, Griswold \& Yin 2009, but can be distinguished from them by the serrated posterior edge of the median apophysis (Fig. 2G). Morphology of the female epigyne and internal genitalia is closely similar to that of $W$. sinensis, but can be identified by the smaller median invagination on the posterior edge of the epigyne and wider scape (Figs. 3A, C, E, arrows). External morphology of the epigyne is also similar to that of $W$. nipponica, but can clearly be distinguished by the relatively shorter copulatory ducts at the basal part of scape (Fig. 3D, F).

Description. Based on the holotype $\delta$ (Fig. 1A) and one of the paratypes $q$ from Ibaraki Pref. (Fig. 1B).

Measurements and Morphology. $\sigma^{\pi} / 9$. Body $1.39 / 1.72$ long, Carapace $0.61 / 0.77$ long; $0.61 / 0.70$ wide and almost as long as wide [length divided by width $1.00 / 1.10$ ]. 
Anterior eye row recurved and posterior eye row straight in the dorsal view. Length of legs: I, $0.31+0.47+0.49+0.28$ $+0.75=2.30 / 0.30+0.36+0.38+0.22+0.62=1.88 ;$ II, $0.29+0.43+0.37+0.20+0.67=1.96 / 0.27+0.34+0.33$ $+0.21+0.54=1.69$; III, $0.22+0.29+0.26+0.16+0.47$ $=1.40 / 0.22+0.26+0.25+0.16+0.38=1.27$; IV, $0.25+$ $0.34+0.33+0.18+0.53=1.63 / 0.24+0.31+0.34+0.19$ $+0.57=1.65$. Length of leg I divided by length of carapace 3.77 / 2.44. Abdomen 0.93 / 1.04 long; 0.88 / 1.15 wide and almost as long as wide [length divided by width 1.18 / 0.99] and oval. Male palp (Fig. 2): tegulum bulbous and occupying almost half of palpal organ; embolic division a complex of apophyses covered with semitransparent conductor and embolus itself hidden by the apparatus; filiform embolic apophysis lying along mesial side of conductor; median apophysis retrolaterally tapered with posterior edge serrated (Fig. 2G); paracymbium hook-like with blunt tip. Female genitalia (Fig. 3): epigyne with a wide plate having a small invagination at posteromedian part, and with a long scape dorsally to the plate; the tip of the scape protruding posteriorly beyond the plate; a pair of spermathecae close to each other; copulatory ducts winding complexly.

Color and markings (Fig. 1). Carapace, sternum, and legs reddish orange but discolored to light yellow after fixed in alcohol. Tip of legs darker. Eye field dark. Male palp dark grey when alive but yellowish brown in fixed specimens. Abdomen glossy dark gray with 2 pairs of sigilla on dorsum, lacking any other clear markings.

Variations $(15 \hat{\delta}$ and $15 \bigcirc)$. $\widehat{\sigma} / q$. Total body length: $1.01-$ 1.47 / 1.29-1.85. Carapace length: 0.54-0.64 / 0.60-0.77; width: $0.52-0.65 / 0.57-0.73$. Abdomen length: 0.50-0.98 / 0.91-1.38; width: 0.52-0.91 / 0.83-1.40. Leg 1 length: 1.83-2.82 / 1.57-2.68. Leg 2 length: 1.51-2.23 / 1.48-2.06. Leg 3 length: 1.19-1.49 / 1.14-1.73. Leg 4 length: 1.27-1.92 / 1.31-2.03.

Distribution. Japan (Ibaraki Pref., Ishikawa Pref., Okayama Pref., Tokyo).
Remarks. Males and females are considered conspecific because of the similarity of general appearance and the fact that no other congeners are sympatrically occurred in the localities. Note that although $W$. nipponica is also recorded from Ibaraki Pref., Okayama Pref. and Tokyo, it is not collected in the habitat of the new species.

Etymology. The specific name is derived from the prosoma color.

\section{Acknowledgements}

I wish to express my heartfelt thanks to Mr. Tatsumi Suguro (Keio Yochisya Elementary School) and Dr. Akio Tanikawa (The University of Tokyo) for their valuable comments on this study. My sincere thanks to Mr. Kouichi Nojima, Mr. Takeaki Ichikawa and Dr. Yuki G. Baba (NARO) for providing invaluable specimens and Mr. Takehisa Hiramatsu for useful information. I would like to thank Editage (www. editage.jp) for English language editing.

\section{References}

Coddington, J. A. 1986. The genera of the spider family Theridiosomatidae. Smithson. Contrib. Zool., 422: 1-96.

Miller, J. A., Griswold, C. E. \& Yin, C. M. 2009. The symphytognathoid spiders of the Gaoligongshan, Yunnan, China (Araneae, Araneoidea): Systematics and diversity of micro-orbweavers. ZooKeys, 11: 9-195.

Shinkai, E. 2009. Two new species of the genera Wendilgarda and Patu from Japan (Aranae: Theridiosomatidae and Symphytognathidae). Pp. 75-77. In: Ono, H. (ed.) The spiders of Japan with keys to the families and genera and illustrations of the species. Tokai University Press, Kanagawa, 738 pp. (In Japanese)

Suguro, T. 2014. Spiders collected from Nakano-shima, Suwanose-jima and Kodakara-jima of Tokara Islands. Kishidaia, 103: 77-79. (In Japanese)

World Spider Catalog 2019. World Spider Catalog. Version 20.0. Natural History Museum Bern,

online at http://wsc.nmbe.ch, accessed on 2019/6/1. doi: 10.24436/2

Zhu, M. S. \& Wang, X. Z. 1992. The spider family Theridiosomatidae first found in China, and with discription [sic] of a new species (Araneae). Acta Arachnol. Sinica, 1: 14-16.

Received June 10, 2019/ Accepted July 29, 2019 